\title{
The baseline levels and risk factors for high-sensitive C-reactive protein in Chinese healthy population
}

Ying Tang ${ }^{1,2+}$, Peifen Liang ${ }^{1,2+}$, Junzhe Chen ${ }^{1,2+}$, Sha Fu ${ }^{1,2}$, Bo Liu ${ }^{1,2}$, Min Feng ${ }^{1,2}$, Baojuan Lin ${ }^{1,2}$, Ben Lee , Anping $X u^{1,2^{*}}$ and Hui Y. $\operatorname{Lan}^{3,4^{*}}$

\begin{abstract}
Background: Recent studies show that C-reactive protein (CRP) is not only a biomarker but also a pathogenic mediator contributing to the development of inflammation and ageing-related diseases. However, serum levels of CRP in the healthy ageing population remained unclear, which was investigated in the present study.

Methods: Serum levels of high sensitive C-reactive protein (hs-CRP), glucose (Glu), triglyceride (TG), cholesterol (CHOL), high-density lipoprotein cholesterol (HDL-c), low-density lipoprotein cholesterol (LDL-c), superoxide dismutase (SOD), serum creatinine (SCr), serum uric acid (SUA) were measured in 6060healthy subjects (3672 male and 2388 female, mean age:45.9 years) who received routine physical examination at Sun Yat-sen Memorial Hospital, Guangzhou, China.

Results: In total of 6060 healthy people, serum levels of hs-CRP were significantly increased with ageing $(P<0.05)$, particularly in those with age over 45-year-old $(1.31[0.69-2.75]$ vs $1.05[0.53-2.16] \mathrm{mg} / \mathrm{L}, P<0.001)$. Interestingly, levels of serum hs-CRP were significantly higher in male than female population (1.24[0.65-2.57] vs 1.07[0.53-2. $29] \mathrm{mg} / \mathrm{L}, P<0.001)$. Correlation analysis also revealed that serum levels of hs-CRP positively correlated with age and SUA, but inversely correlated with serum levels of HDL-C and SOD (all $P<0.05$ ).

Conclusions: Baseline levels of serum hs-CRP are increased with ageing and are significantly higher in male than female healthy population. In addition, elevated serum levels of hs-CRP are also associated with increased SUA but decreased HDL-c and SOD. Thus, serum levels of hs-CRP may be an indicator associated with ageing in healthy Chinese population.
\end{abstract}

Keywords: Hs-CRP, Ageing, Inflammation, Risk factor

\section{Background}

Ageing is a natural phenomenon characterized by gradual deterioration of the body structure and function with important social, public health, and economic implications. Increasing evidence shows that inflammation is one of the key mechanisms associated with many ageing-related diseases, including cancer, atherosclerosis, hypertension, diabetes mellitus, ischemic heart disease, cirrhosis, Alzheimer's disease and other dementias and chronic diseases [1,

\footnotetext{
* Correspondence: anpxu@163.com; hylan@cuhk.edu.hk

${ }^{\dagger}$ Ying Tang, Peifen Liang and Junzhe Chen contributed equally to this work.

'Department of Nephrology, Sun Yat-sen Memorial Hospital, Sun Yat-sen University, Guangzhou, China

${ }^{3}$ Department of Medicine and Therapeutics, Li KaShing Institute of Health Sciences, the Chinese University of Hong Kong, Hong Kong, SAR, China Full list of author information is available at the end of the article
}

2].Therefore, disentangling age-related low grade inflammation may slow or delay ageing process [2]. Many inflammatory effector molecules and biomarkers, especially C-reactive protein (CRP), interleukin-6 (IL-6) and tumor necrosis factor-alpha (TNF- $\alpha$ ), have been considered as important factors associated with ageing, ageing-related diseases or disability [3]. CRP, an acute phase protein, is primarily produced and secreted by the liver in response to IL-6.Serum levels of CRP can be measured by a high sensitivity immunoturbidometric assay termed high-sensitive CRP (hs-CRP). Many studies have shown that elevated levels of serum hs-CRP are associated with ageing and ageing-related diseases including cardiovascular disease (CVD), hypertension, diabetes mellitus, and kidney disorders [4-8].However, there is still a lack of evidence

(c) The Author(s). 2018 Open Access This article is distributed under the terms of the Creative Commons Attribution 4.0 International License (http://creativecommons.org/licenses/by/4.0/), which permits unrestricted use, distribution, and 
for the relationship between the baseline levels of hs-CRP and the ageing progress in general healthy population, which was investigated in this study. In addition, although many inflammatory mediators including dyslipidemia, insulin resistance, oxidative stress, and serum uric acid (SUA) have also been shown to contribute to high levels of serum hs-CRP under various disease conditions [9-16]. The link between hs-CRP and these factors in the healthy population remains unknown, which was also analyzed in this study.

\section{Methods}

\section{Study population}

This was a retrospective study in the healthy Chinese population who underwent routine health examination carried out between April 1st, 2009 and May 1st, 2017 at Sun Yat-sen Memorial Hospital, Sun Yat-sen University, Guangzhou, China. As described previously [1719], the population enrolled into this study included the healthy subjects aged 18-89 years old without evidence of acute infection, cardiovascular disease, chronic kidney disease, cancer, diabetes, gout, obstructive pulmonary disease and Alzheimer's disease based on the previous medical record in Sun Yat-sen Memorial Hospital. Those with various diseases and abnormal medical laboratory tests such as eGFR less than $60 \mathrm{ml} / \mathrm{min} / 1.73 \mathrm{~m}^{2}$ were excluded from this study. The study protocol was approved by the Institutional Review Boards of the Sun Yat-sen Memorial Hospital and waived the need for informed consent and conducted in accordance with the principles embodied in the Declaration of Helsinki (2013).

\section{Methods}

Serum levels of glucose (Glu), triglyceride (TG), highdensity lipoprotein cholesterol (HDL-c), low-density lipoprotein cholesterol (LDL-c), superoxide dismutase (SOD), serum creatinine (SCr), SUA, hs-CRP in fasting blood samples were measured by automated biochemical Analyzer 5800 (BECKMAN) or 7600 (HITACHI). The normal references of serum hs-CRP levels were set at $0-$ $3.0 \mathrm{mg} / \mathrm{L}$. The value of estimated glomerular filtration rate (eGFR) was calculated using the North American Chronic Kidney Disease Epidemiology (CKD-EPI) Collaboration equation.

\section{Statistical analysis}

The baseline characteristics of healthy population and subgroups were analyzed by using SPSS version 19 (IBM Corporation, Armonk, New York, USA). For continuous variables with symmetric distribution, mean data were expressed as mean \pm standard deviations $(S D)$, whereas median and interquartile range $(I Q R)$ was used for those with asymmetric distribution and examined by Student's t-test, analysis of variance (ANOVA), chi-square test. Factors found to be statistically significant from univariate analysis
$(P<0.05)$ were then tested in multivariate analysis using Linear regression analysis modeling. The correlations between hs-CRP and other risk factors were shown in the scatter plots with linear regression line and $P$-value of $<0.05$ from two-sided tests was considered statistically significant.

\section{Results}

\section{Baseline characteristics of healthy population}

A total of 6060 healthy people who underwent routine health check were included in this study. Of them, 3672 cases (60.4\%) were male and 2388 (39.4\%) were female, and the age ranged from 18 to 89 years old with the mean age of 45 -year-old. Since age of 45 years old is known to be one of the risks for the development of atherosclerotic cardiovascular diseases in men and is the mean menopause age in women with declining steroid hormones and increasing pro-inflammatory markers [3], therefore the age of 45-year-old was stratified as a subgroup for the risk factor of hs-CRP. As shown in Fig. 1, serum levels of hs-CRP were increased with ageing. Compared to male, female population exhibited higher levels of HDL-c and eGFR $(P<0.05)$ but lower levels of hs-CRP, TG, CHOL, LDL-c, SOD, Glu and SUA $(P<$ $0.05)$. The population with age $>45$-year-old had higher levels of hs-CRP, TG, CHOL, LDL-c and Glu $(P<0.05)$, but lower levels of eGFR and SOD $(P<0.05)$ compared to age between 18 and 45 . There were no differences in levels of SUA and HDL-c $(P>0.05)$ between these two groups (Table 1).

\section{Risk factors of hs-CRP in the overall healthy population}

As shown in Table 2, the univariate linear regression analysis showed that age and levels of SUA and Glu were positively correlated with levels of serum hs-CRP $(P<$ $0.05)$, whereas, serum levels of HDL-c and SOD were negatively correlated with levels of serum hs-CRP $(P<$ $0.05)$. The multivariate linear regression analysis further identified significant correlations between hs-CRP and age $(\beta=0.033, P=0.012)$, the levels of HDL-c $(\beta=-$ $0.062, P<0.001)$, SOD $(\beta=-0.100, P<0.001)$ and SUA $(\beta=0.033, P=0.015)$.

\section{Risk factors of hs-CRP in healthy population stratified by gender}

Considering the possible effects of gender on serum hs-CRP levels, we analyzed the risk factor of hs-CRP in male and female respectively. In the male subgroup, the multivariate linear regression analysis showed that serum levels of hs-CRP correlated significantly with the age $(\beta=$ $0.037, P=0.026)$ and SUA $(\beta=0.034, P=0.042)$, but negatively correlated with the levels of HDL-c $(\beta=-0.041, P=$ $0.014)$ and $\operatorname{SOD}(\beta=-0.086, P<0.001)$ (Additional file 1 : Table S1).The correlations between hs-CRP and these 


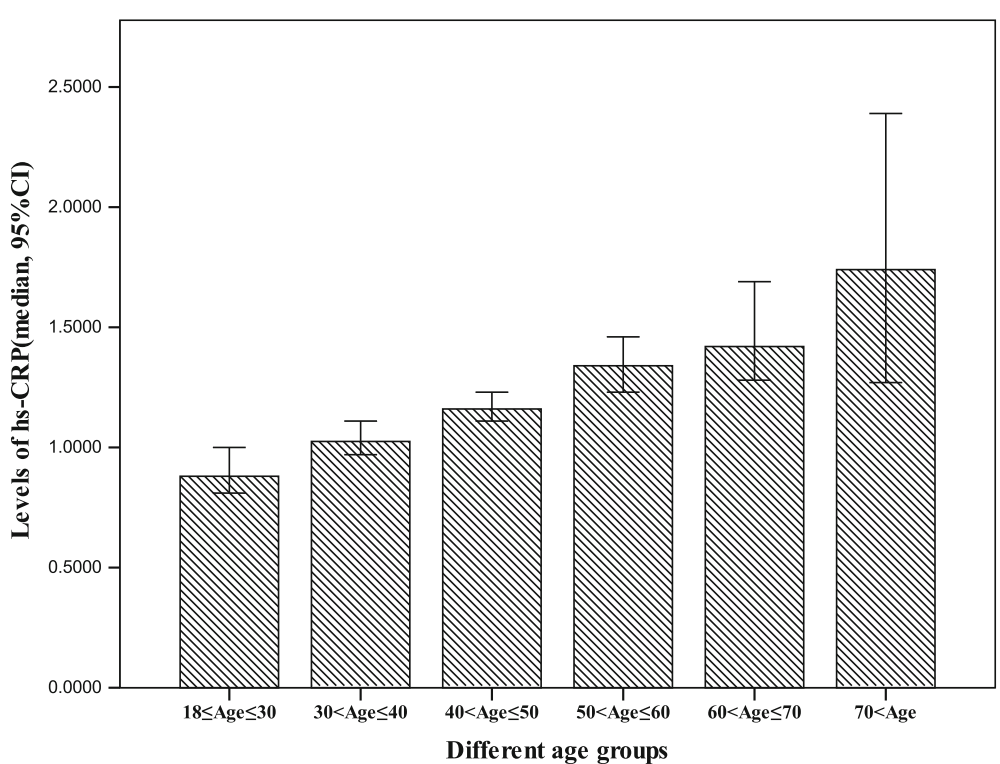

Fig. 1 hs-CRP levels in different age groups. Each bar represents the median and $95 \% \mathrm{Cl}$ as indicated. ${ }^{*} p<0.05$, ${ }^{* *} p<0.001$ compared to the age subgroup of 18-30 year-old population

factors in the male population were shown in Figure 2.Similarly, in the female subgroup, results from the multivariate linear regression analysis were generally consistent with the male subgroup (Additional file 1: Table S1).Figure 3 showed the correlations between hs-CRP and these factors in the female population.

\section{Risk factors of hs-CRP in healthy population stratified by age and gender}

A higher level of hs-CRP was associated with ageing and male in 6060 healthy population (Table 1), further analysis was performed to identify the co-risk factors for hs-CRP in healthy people stratified by the mean age and gender. In healthy population with age of less than 45-year-old, the univariate linear regression analysis showed that levels of hs-CRP positively correlated with SUA $(P<0.05)$, but negatively with levels of HDL-c and SOD $(P<0.05)$ in both genders, which were further confirmed by the multivariate linear regression analysis (Tables 3 and 4). Similar results were also found in those with age more than 45-year-old subpopulation (Tables 3 and 4).

Table 1 Baseline characteristics of healthy population

\begin{tabular}{|c|c|c|c|c|c|c|c|}
\hline & \multirow[t]{2}{*}{ Overall $(n=6060)$} & \multicolumn{3}{|l|}{ Sex subgroup } & \multicolumn{3}{|l|}{ Age subgroup } \\
\hline & & Male $(n=3672)$ & Female $(n=2388)$ & $P$ & $\begin{array}{l}18 \leq \mathrm{Age} \leq 45 \\
(n=3046)\end{array}$ & $45<$ Age $(n=3014)$ & $P$ \\
\hline Age, y & $45.90 \pm 11.16$ & $45.40 \pm 10.97$ & $46.67 \pm 11.41$ & $<0.001$ & $36.98 \pm 6.06$ & $54.92 \pm 7.18$ & $<0.001$ \\
\hline hs-CRP, mg/L & $1.18(0.60,2.47)$ & $1.24(0.65,2.57)$ & $1.07(0.53,2.29)$ & $<0.001$ & $1.05(0.53,2.16)$ & $1.31(0.69,2.75)$ & $<0.001$ \\
\hline $\mathrm{TG}, \mathrm{mmol} / \mathrm{L}$ & $1.33(0.93,1.99)$ & $1.53(1.07,2.27)$ & $1.08(0.80,1.57)$ & $<0.001$ & $1.26(0.87,1.97)$ & $1.39(0.99,2.02)$ & $<0.001$ \\
\hline $\mathrm{CHOL}, \mathrm{mmol} / \mathrm{L}$ & $5.35 \pm 1.11$ & $5.39 \pm 1.13$ & $5.28 \pm 1.08$ & $<0.001$ & $5.19 \pm 1.09$ & $5.50 \pm 1.11$ & $<0.001$ \\
\hline $\mathrm{HDL}-\mathrm{C}, \mathrm{mmol} / \mathrm{L}$ & $1.35 \pm 0.33$ & $1.26 \pm 0.29$ & $1.49 \pm 0.34$ & $<0.001$ & $1.35 \pm 0.32$ & $1.36 \pm 0.34$ & 0.204 \\
\hline $\mathrm{LDL}-\mathrm{C}, \mathrm{mmol} / \mathrm{L}$ & $3.35 \pm 0.85$ & $3.42 \pm 0.85$ & $3.25 \pm 0.85$ & $<0.001$ & $3.24 \pm 0.84$ & $3.47 \pm 0.85$ & $<0.001$ \\
\hline $\mathrm{SOD}, \mathrm{U} / \mathrm{mL}$ & $158.67 \pm 32.55$ & $161.33 \pm 36.06$ & $154.57 \pm 25.72$ & $<0.001$ & $162.81 \pm 21.05$ & $154.48 \pm 40.59$ & $<0.001$ \\
\hline $\begin{array}{l}\mathrm{eGFR}, \mathrm{ml} / \\
\mathrm{min} \cdot 1.73 \mathrm{~m}^{2}\end{array}$ & $83.89 \pm 15.04$ & $82.50 \pm 14.50$ & $86.02 \pm 15.60$ & $<0.001$ & $88.55 \pm 15.77$ & $79.18 \pm 12.63$ & $<0.001$ \\
\hline$S U A, \mu \mathrm{mol} / \mathrm{L}$ & $369.00(307.00,436.75)$ & $409.00[358.00,466.00]$ & $305.00[263.00,353.00]$ & $<0.001$ & $370.00[303.00,444.00]$ & $367.50(310.00,429.00)$ & 0.184 \\
\hline Glu, mmol/L & $5.50 \pm 1.58$ & $5.65 \pm 1.82$ & $5.28 \pm 1.09$ & $<0.001$ & $5.26 \pm 1.31$ & $5.74 \pm 1.78$ & $<0.001$ \\
\hline
\end{tabular}


Table 2 The relationship between hs-CRP and biomarkers in healthy population $(N=6060)$

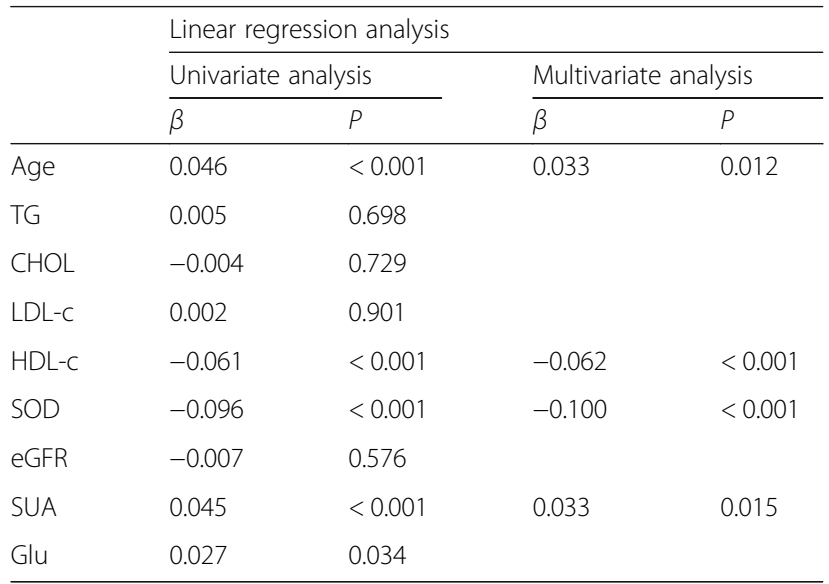

\section{Discussion}

The present cross-sectional study revealed that serum levels of hs-CRP were increased with ageing and higher in male than female in Chinese healthy population. Our results showed that higher serum levels of hs-CRP were strongly associated with higher levels of SUA, lower levels of HDL-c and enzymatic antioxidants SOD. These results suggested that elevated serum levels of SUA might trigger CRP production, whereas serum HDL-c and SOD might have an opposite effect. Thus, serum levels of hs-CRP may be a useful indicator for ageing in healthy population.

Ageing is thought to be related to the inflammatory processes. Numerous studies have shown that levels of several cytokines, especially IL-6, TNF alpha and CRP, increase with age in the absence of acute infection [20, 21]. In the present study, we found that elevated levels of hs-CRP levels were correlated with ageing. Interestingly, consistent with previous population-based studies [22, 23], we also found that high serum levels of CRP were significantly correlated with elevated levels of SUA

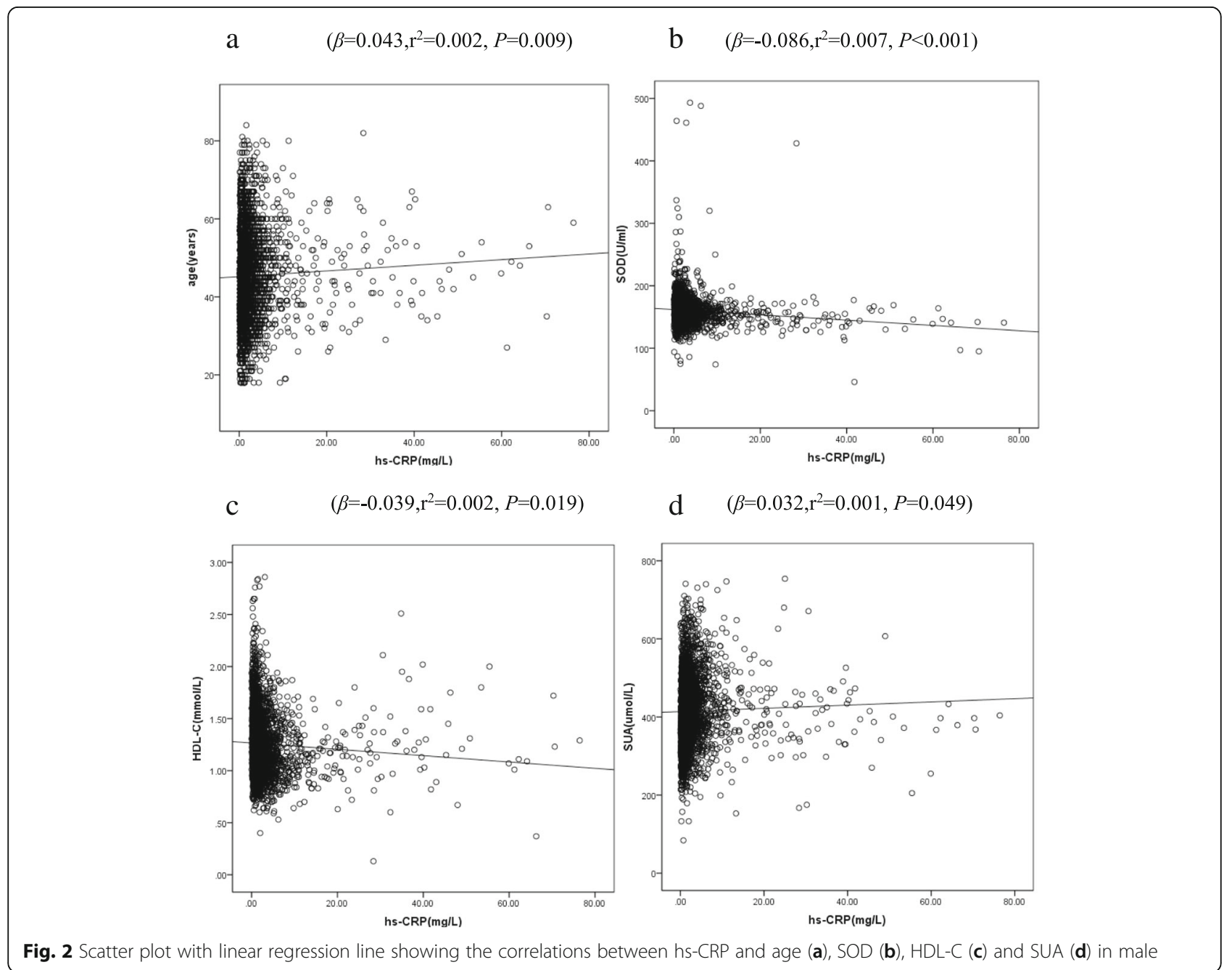


a

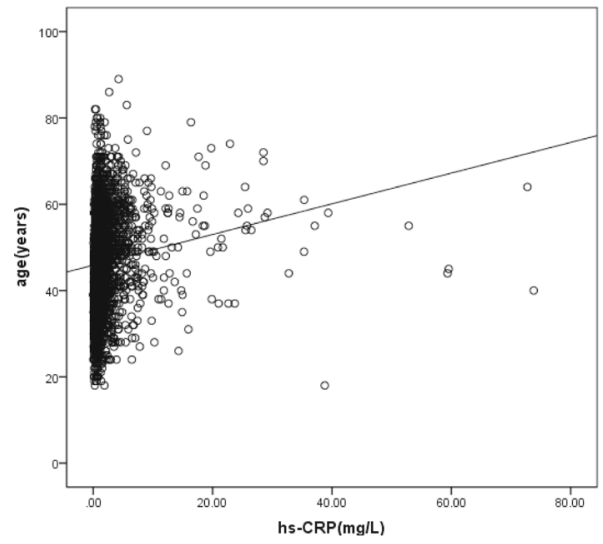

C $\quad\left(\beta=-0.087, \mathrm{r}^{2}=0.008, P<0.001\right)$

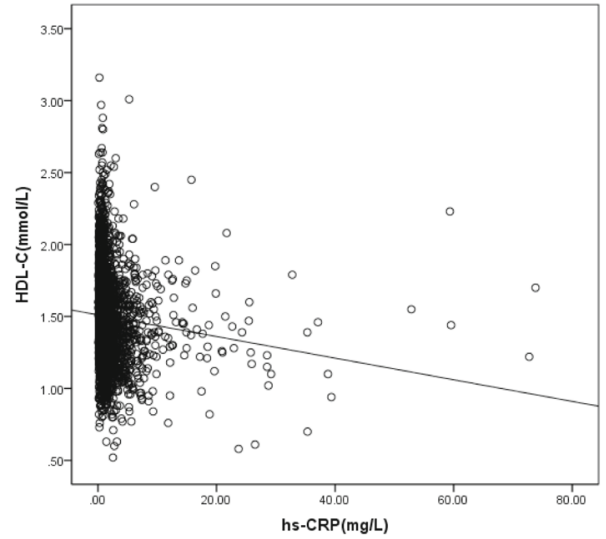

b $\quad\left(\beta=-0.136, \mathrm{r}^{2}=0.018, P<0.001\right)$

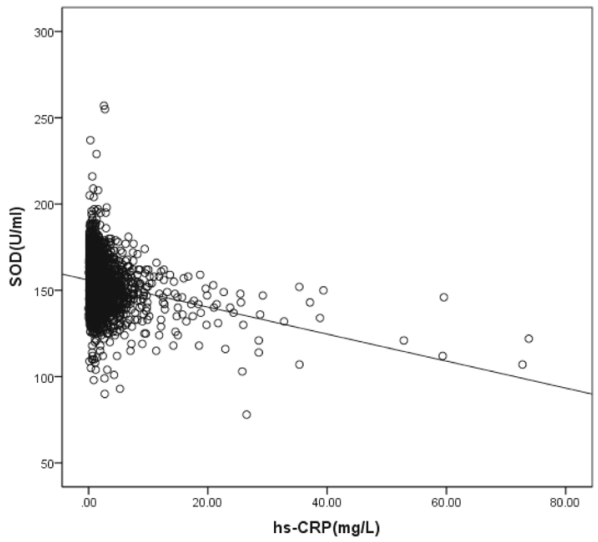

d $\quad\left(\beta=0.079, \mathrm{r}^{2}=0.006, P<0.001\right)$

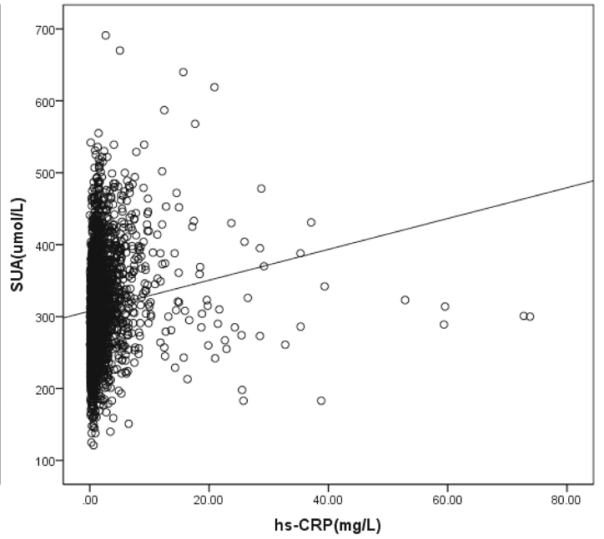

Fig. 3 Scatter plot with linear regression line showing the correlations between hs-CRP and age (a), SOD (b), HDL-C (c) and SUA (d) in female

but low levels of HDL-c and SOD. Hyperuricemia has been shown to contribute to the development of hypertension, chronic kidney disease, cardiovascular diseases, type 2 diabetes mellitus and the metabolic syndrome by inducing endothelial dysfunction and pathologic vascular remodeling [24-27]. Thus, SUA and CRP may share common features in vascular remodeling, and it is possible that SUA may trigger CRP expression. Currently, evidence from experimental studies has shown that mitogen-activated protein kinases (MAPK) signaling is a

Table 3 The relationship between hs-CRP and biomarkers in healthy male population

\begin{tabular}{|c|c|c|c|c|c|c|c|c|}
\hline & \multicolumn{4}{|c|}{ Linear regression analysis( $18 \leq$ age $\leq 45)(n=1945)$} & \multicolumn{4}{|c|}{ Linear regression analysis $($ age $>45)(n=1727)$} \\
\hline & \multicolumn{2}{|c|}{ Univariate analysis } & \multicolumn{2}{|c|}{ Multivariate analysis } & \multicolumn{2}{|c|}{ Univariate analysis } & \multicolumn{2}{|c|}{ Multivariate analysis } \\
\hline & $\bar{\beta}$ & $P$ & $\bar{\beta}$ & $P$ & $\bar{\beta}$ & $P$ & $\bar{\beta}$ & $P$ \\
\hline Age & 0.004 & 0.846 & & & 0.023 & 0.346 & & \\
\hline TG & 0.004 & 0.847 & & & -0.018 & 0.461 & & \\
\hline $\mathrm{CHOL}$ & -0.005 & 0.811 & & & -0.037 & 0.120 & & \\
\hline LDL-C & -0.002 & 0.935 & & & -0.039 & 0.108 & & \\
\hline $\mathrm{HDL}-\mathrm{C}$ & -0.064 & 0.005 & -0.060 & 0.008 & -0.081 & 0.001 & -0.081 & 0.001 \\
\hline SOD & -0.140 & $<0.001$ & -0.143 & $<0.001$ & -0.065 & 0.007 & -0.074 & 0.002 \\
\hline eGFR & -0.012 & 0.594 & & & 0.004 & 0.860 & & \\
\hline UA & 0.078 & 0.001 & 0.065 & 0.004 & 0.055 & 0.021 & 0.049 & 0.041 \\
\hline Glu & 0.031 & 0.177 & & & 0.010 & 0.671 & & \\
\hline
\end{tabular}


Table 4 The relationship between hs-CRP and biomarkers in healthy female population

\begin{tabular}{|c|c|c|c|c|c|c|c|c|}
\hline & \multicolumn{4}{|c|}{ Linear regression analysis $(18 \leq$ age $\leq 45)(n=1101)$} & \multicolumn{4}{|c|}{ Linear regression analysis $($ age $>45)(n=1287)$} \\
\hline & \multicolumn{2}{|c|}{ Univariate analysis } & \multicolumn{2}{|c|}{ Multivariate analysis } & \multicolumn{2}{|c|}{ Univariate analysis } & \multicolumn{2}{|c|}{ Multivariate analysis } \\
\hline & $\bar{\beta}$ & $P$ & $\bar{\beta}$ & $P$ & $\beta$ & $P$ & $\bar{\beta}$ & $P$ \\
\hline Age & 0.016 & 0.596 & & & 0.079 & 0.005 & & \\
\hline TG & 0.027 & 0.374 & & & 0.023 & 0.410 & & \\
\hline $\mathrm{CHOL}$ & 0.034 & 0.256 & & & -0.002 & 0.937 & & \\
\hline LDL-C & 0.041 & 0.179 & & & 0.017 & 0.547 & & \\
\hline HDL-C & -0.110 & $<0.001$ & -0.112 & $<0.001$ & -0.129 & $<0.001$ & -0.120 & $<0.001$ \\
\hline SOD & -0.165 & $<0.001$ & -0.169 & $<0.001$ & -0.139 & $<0.001$ & -0.140 & $<0.001$ \\
\hline eGFR & 0.043 & 0.154 & & & -0.029 & 0.297 & & \\
\hline UA & 0.084 & 0.005 & 0.062 & 0.037 & 0.142 & $<0.001$ & 0.109 & $<0.001$ \\
\hline Glu & 0.006 & 0.852 & & & 0.045 & 0.103 & & \\
\hline
\end{tabular}

common pathway by which uric acid triggers CRP production in vascular smooth muscle cells and vein endothelial cells [28-30]. It has also been shown that the addition of UA is able to stimulate the expression of CRP by activating the proinflammatory NF- $\mathrm{KB}$ signaling cascade [31]. Also, we recently revealed the pathogenic role for CRP in acute and chronic kidney diseases via a NF-kB-dependent mechanism [32-34]. Furthermore, changes of hs-CRP have been applied as a biomarker clinically as evidenced by the lowering of serum CRP in response to various treatments under disease conditions [35-39].Taken together, results from the present study suggested that CRP might not only be a biomarker and mediator for inflammatory disease, but also as a sensitive indicator for the healthy ageing.

The gender difference with respect to the serum levels of CRP has not been fully clarified. Previous studies have shown a higher prevalence of high hs-CRP concentrations in Inuit or Pakistan women populations than that in men [40, 41]. In our study, we found that higher levels of hs-CRP were more prevalent in male than female individuals. This maybe partly attributed to the higher level of SUA but lower level of HDL-c. Previous studies also reported that circulating levels of CRP in elderly subjects were positively correlated with levels of blood glucose and HbA1c, but inversely correlated with renal dysfunction [42-45]. However, in this population-based study, we could not find any relationship between hs-CRP and Glu or eGFR. This may be largely due to the normal levels of Glu and eGFR in the healthy population.

There are some limitations in this study. First, since this study was retrospectively based on the healthy population who underwent routine healthy examination at clinic, we are unable to acquire data regarding BMI, smoking habit, and other information that are potentially associated with the occurrence of inflammation and their consequences [3]. Second, since CRP was co-existing with other inflammatory conditions, our retrospective data may not be able to exclude those with minor acute inflammation, although the enrolled subjects were apparently healthy. Finally, since the majority of our study subjects were limited to those with age between 30 and 60 years old, the study outcomes may be more generalized to young and middle-aged healthy people, despite the fact that high serum levels of CRP were found in the population with age more than 65 years old.

\section{Conclusions}

This retrospective study shows that serum levels of hs-CRP are increased with ageing, particularly in male than female healthy population. Furthermore, elevated serum levels of hs-CRP are associated with high levels of SUA, but low levels of HLD-c and SOD, suggesting that the inflammatory status may also contribute to ageing in the healthy population.

\section{Additional file}

Additional file 1: Table S1. The relationship between hs-CRP and biomarkers stratified by gender in healthy population. Table S2. The relationship between hs-CRP and biomarkers stratified by age in healthy population. (DOCX $20 \mathrm{~kb}$ )

\section{Abbreviations}

ANOVA: Analysis of variance; CHOL: Cholesterol; CRP: C-reactive protein CVD: Cardiovascular disease; eGFR: Estimated glomerular filtration rate; Glu: Glucose; HDL-c: High-density lipoprotein cholesterol; hs-CRP: High sensitive C-reactive protein; IL-6: Interleukin-6; IQR: Interquartile range; LDL-c: Low-density lipoprotein cholesterol; SCr: Serum creatinine; SD: Standard deviation; SOD: Superoxide dismutase; SUA: Serum uric acid; TG: Triglyceride

\section{Acknowledgements}

We would like to thank Professor Li Ling and Dr. Cheng Gong for the assistance in statistical analysis and data interpretation and Thomas Mak for English editing. 


\section{Funding}

This study was supported by grants from National Natural Scientific Foundation of China (81500512); and the Fundamental Research Funds for the Central Universities(17ykjc19); the LuiChe Woo Institute of Innovative Medicine (CARE program); Research Grants Council of Hong Kong (GRF 14121816,C7018-16G, TRS T12-402/13 N); and Health and Medical Research Fund of Hong Kong (HMRF 03140486, 14152321).

\section{Availability of data and materials}

Please contact author for data requests.

\section{Authors' contributions}

Study design: YT. Data analysis and interpretation: YT, JZ C, PF L, SF, Ben L Data collection: JZ C, PF L, SF, BL, MF, BJ L, Ben L. Manuscript preparation: YT, PF L, JZ C, SF, BL, HY L, AP X. Manuscript revision: YT, JZ C, HY L, AP X. Statistical analysis: JZ C, SF, BL. All authors read and approved the final manuscript.

\section{Ethics approval and consent to participate}

The institutional Review Boards of Sun Yat-sen Memorial Hospital approved this study and waived the need for informed consent.

\section{Consent for publication}

Not applicable.

\section{Competing interests}

The authors declare that they have no competing interests.

\section{Publisher's Note}

Springer Nature remains neutral with regard to jurisdictional claims in published maps and institutional affiliations.

\section{Author details}

'Department of Nephrology, Sun Yat-sen Memorial Hospital, Sun Yat-sen University, Guangzhou, China. ${ }^{2}$ Guangdong Provincial Key Laboratory of Malignant Tumor Epigenetics and Gene Regulation, Sun Yat-sen Memorial Hospital, Sun Yat-sen University, Guangzhou, China. ${ }^{3}$ Department of Medicine and Therapeutics, Li KaShing Institute of Health Sciences, the Chinese University of Hong Kong, Hong Kong, SAR, China. ${ }^{4}$ Lui Che Woo Institute of Innovative Medicine, the Chinese University of Hong Kong, Hong Kong, SAR, China. ${ }^{5}$ Guangzhou Deling Software Technology Co., Ltd, Guangzhou, China.

\section{Received: 31 March 2018 Accepted: 23 August 2018}

\section{Published online: 08 September 2018}

\section{References}

1. Franceschi C, Bonafè M, Valensin S, Olivieri F, De Luca M, Ottaviani $E$, et al. Inflamm-aging. An evolutionary perspective on immunosenescence. Ann N Y AcadSci. 2000;908:244-54.

2. Candore G, Caruso C, Jirillo E, Magrone T, Vasto S. Low grade inflammation as a common pathogenetic denominator in age-related diseases: novel drug targets for anti-ageing strategies and successful ageing achievement. Curr Pharm Des. 2010;16(6):584-96.

3. Singh T, Newman AB. Inflammatory markers in population studies of aging Ageing Res Rev. 2011;10(3):319-29.

4. Tang Y, Fung E, Xu A, Lan HY. C-reactive protein and ageing. Clin Exp Pharmacol Physiol. 2017:4 https://doi.org/10.1111/1440-1681.12758.

5. Hamer M, Chida Y. Associations of very high C-reactive protein concentration with psychosocial and cardiovascular risk factors in an ageing population. Atherosclerosis. 2009;206(2):599-603.

6. Sujarwoto S, Tampubolon G. Inflammatory markers and physical performance in middle-aged and older people in Indonesia. Age Ageing. 2015;44(4):610-5.

7. Buffière C, Mariotti F, Savary-Auzeloux I, Migné C, Meunier N, Hercberg S, et al. Slight chronic elevation of C-reactive protein is associated with lower aerobic fitness but does not impair meal-induced stimulation of muscle protein metabolism in healthy old men. J Physiol. 2015;593(5):1259-72.

8. Sousa AC, Zunzunegui MV, Li A, Phillips SP, Guralnik JM, Guerra RO. Association between C-reactive protein and physical performance in older populations: results from the international mobility in aging study (IMIAS). Age Ageing. 2016;45(2):274-80.
9. Tsioufis C, Kyvelou S, Dimitriadis K, Syrseloudis D, Sideris S, Skiadas I, et al. The diverse associations of uric acid with low-grade inflammation, adiponectin and arterial stiffness in never-treated hypertensives. J Hum Hypertens. 2011;25(9):554-9.

10. Latourte A, Soumaré A, Bardin T, Perez RF, Debette S, Richette P. Uric acid and incident dementia over 12 years of follow-up: a population-based cohort study. Ann Rheum Dis. 2017;28 https://doi.org/10.1136/annrheumdis2016-210767.

11. Mirhafez SR, Ebrahimi M, Saberi KM, Avan A, Tayefi M, Heidari BA, et al. Serum high-sensitivity C-reactive protein as a biomarker in patients with metabolic syndrome: evidence-based study with 7284 subjects. Eur J ClinNutr. 2016;70(11):1298-304.

12. Agirbasli M, Tanrikulu A, Acar SB, Azizy M, Bekiroglu N. Total cholesterol-tohigh-density lipoprotein cholesterol ratio predicts high-sensitivity $C$-reactive protein levels in Turkish children. J ClinLipidol. 2015;9(2):195-200.

13. Lodovici M, Bigagli E, Luceri C, Mannucci E, Rotella CM, Raimondi L. Genderrelated drug effect on several markers of oxidation stress in diabetes patients with and without complications. Eur J Pharmacol. 2015;766:86-90.

14. Caccamo G, Bonura F, Bonura F, Vitale G, Novo G, Evola S, et al. Insulin resistance and acute coronary syndrome. Atherosclerosis. 2010;211(2):672-5.

15. Liu Q, Han L, Du Q, Zhang M, Zhou S, Shen X. The association between oxidative stress, activator protein-1, inflammatory, total antioxidant status and artery stiffness and the efficacy of olmesartan in elderly patients with mild-tomoderate essential hypertension. Clin Exp Hypertens. 2016;38(4):365-9.

16. Peng C, Wang X, Chen J, Jiao R, Wang L, Li YM, et al. Biology of ageing and role of dietary antioxidants. Biomed Res Int. 2014;831841 https://doi.org/10. 1155/2014/831841.

17. Bousquet J, Malva J, Nogues M, Mañas LR, Vellas B, Farrell J, MACVIA Research Group. Operational Definition of Active and Healthy Aging (AHA): The European Innovation Partnership(EIP) on AHA Reference Site Questionnaire: Montpellier October 20-21, 2014, Lisbon July 2, 2015. J Am Med Dir Assoc. 2015;16(12):1020-6.

18. Malik R, Aneni EC, Shahrayar S, Freitas WM, Ali SS, Veledar E, et al. Elevated serum uric acid is associated with vascular inflammation but not coronary artery calcification in the healthy octogenarians: the Brazilian study on healthy aging. Aging Clin Exp Res. 2016;28(2):359-62.

19. Cicero AF, Rosticci M, Cagnati M, Urso R, Scapagnini G, Morbini M, et al. Serum uric acid and markers of low-density lipoprotein oxidation in nonsmoking healthy subjects: data from the Brisighella heart study. Pol Arch Med Wewn. 2014;124(12):661-8.

20. Ferrucci L, Corsi A, Lauretani F, Bandinelli S, Bartali B, Taub DD, et al. The origins of age-related proinflammatory state. Blood. 2005;105(6):2294-9.

21. Fagiolo U, Cossarizza A, Scala E, Fanales BE, Ortolani C, Cozzi E, et al. Increased cytokine production in mononuclear cells of healthy elderly people. Eur J Immunol. 1993;23(9):2375-8.

22. Fröhlich $M$, Imhof $A$, Berg $G$, Hutchinson WL, Pepys MB, Boeing $H$, et al. Association between C-reactive protein and features of the metabolic syndrome: a population-based study. Diabetes Care. 2000;23(12):1835-9.

23. Ruggiero C, Cherubini A, Ble A, Bos AJ, Maggio M, Dixit VD, et al. Uric acid and inflammatory markers. Eur Heart J. 2006;27(10):1174-81.

24. Tsai WC, Huang YY, Lin CC, Li WT, Lee CH, Chen JY, et al. Uric acid is an independent predictor of arterial stiffness in hypertensive patients. Heart Vessel. 2009:24(5):371-5.

25. Kanbay M, Yilmaz MI, Sonmez A, Turgut F, Saglam M, Cakir E, et al. Serum uric acid level and endothelial dysfunction in patients with nondiabetic chronic kidney disease. Am J Nephrol. 2011;33(4):298-304.

26. Ma QQ, Yang XJ, Yang NQ, Liu L, Li XD, Zhu K, et al. Study on the levels of uric acid and high-sensitivity C-reactive protein in ACS patients and their relationships with the extent of the coronary artery lesion. Eur Rev Med Pharmacol Sci. 2016;20(20):4294-8.

27. Dehghan A, Van HM, Sijbrands EJ, Hofman A, Witteman JC. High serum uric acid as a novel risk factor for type 2 diabetes. Diabetes Care. 2008;31(2):361-2.

28. Kang DH, Park SK, Lee IK, Johnson RJ. Uric acid-induced C-reactive protein expression: implication on cell proliferation and nitric oxide production of human vascular cells. J Am SocNephrol. 2005;16(12):3553-62.

29. Johnson RJ, Rodriguez-Iturbe B, Kang DH, Feig DI, Herrera-Acosta J. A unifying pathway for essential hypertension. Am J Hypertens. 2005;18(3) 431-40.

30. Kanellis J, Watanabe S, Li JH, Kang DH, Li P, Nakagawa T, Wamsley A, Sheikh-Hamad D, Lan HY, Feng L, Johnson RJ. Uric acid stimulates monocyte chemoattractant protein-1 production in vascular smooth muscle 
cells via mitogen-activated protein kinase and cyclooxygenase-2. Hypertension. 2003;41(6):1287-93.

31. Spiga R, Marini MA, Mancuso E, Di FC, Fuoco A, Perticone F, et al. Uric acid is associated with inflammatory biomarkers and induces inflammation via activating the NF-KB signaling pathway in HepG2 cells. Arterioscler Thromb Vasc Biol. 2017;37(6):1241-9.

32. Lai $W$, Tang $Y$, Huang XR, Ming-Kuen Tang $P$, Xu A, Szalai AJ, et al. C-reactive protein promotes acute kidney injury via Smad3-dependent inhibition of CDK2/cyclinE. Kidney Int. 2016;90(3):610-26.

33. Liu F, Chen HY, Huang XR, Chung AC, Zhou L, Fu P, et al. C-reactive protein promotes diabetic kidney disease ina mouse model of type 1 diabetes. Diabetologia. 2011;54(10):2713-23.

34. Li Z, Chung AC, Zhou L, Huang XR, Liu F, Fu P, et al. C-reactive protein promotes acute renal inflammation and fibrosis in unilateral ureteral obstructive nephropathy in mice. Lab Investig. 2011;91(6):837-51.

35. El-Sheakh AR, Ghoneim HA, Suddek GM, Ammar ES. Attenuation of oxidative stress, inflammation, and endothelial dysfunction inhypercholesterolemic rabbits by allicin. Can J Physiol Pharmacol. 2016; 94(2):216-24.

36. Lu YX, Zhang Q, Li J, Sun YX, Wang LY, Cheng WM, Hu XY. Antidiabetic effects of total flavonoids from Litsea Coreana leve on fat-fed, streptozotocin-induced type 2 diabetic rats. Am J Chin Med. 2010;38(4): 713-25.

37. Bian GX, Li GG, Yang Y, Liu RT, Ren JP, Wen LQ, Guo SM, Lu QJ. Madecassoside reduces ischemia-Reperfusioninjury on regional ischemia induced heartinfarction in rat. Biol Pharm Bull. 2008;31(3):458-63.

38. Wang D, Zhang X, Li D, Hao W, Meng F, Wang B, Han J, Zheng Q. Kaempferide protects against myocardial ischemia/reperfusion injury through activation of the PI3K/Akt/GSK-3 $\beta$ pathway. Mediat Inflamm 2017; 5278218. doi: https://doi.org/10.1155/2017/5278218.

39. El-Awady MS, Nader MA, Sharawy MH. The inhibition of inducible nitric oxide synthase and oxidative stress by agmatine attenuates vascular dysfunction in rat acute endotoxemicmodel. Environ Toxicol Pharmacol. 2017;10(55):74-80.

40. Labonté ME, Dewailly E, Chateau DM, Couture P, Lamarche B. Populationbased study of high plasma C-reactive protein concentrations among the Inuit of Nunavik. Int J Circumpolar Health. 2012:71. https://doi.org/10.3402/ ijch.v71i0.19066.

41. Riaz M, Fawwad A, Hydrie MZ, Basit A, Shera AS. Is there any association of serum high-sensitivity $\mathrm{C}$-reactive protein with various risk factors for metabolic syndrome in a healthy adult population of karachi, Pakistan? Metab Syndr Relat Disord. 2011;9(3):177-82.

42. Wijsman CA, Mooijaart SP, Westendorp RG, Maier AB. Responsiveness of the innate immune system and glucose concentrations in the oldest old. Age (Dordr). 2012;34(4):983-6.

43. Costello WR, Ryff CD, Coe CL. Aging and low-grade inflammation reduce renal function in middle-aged and older adults in Japan and the USA. Age (Dordr). 2015;37(4):9808.

44. Liu W, Yu F, Wu Y, Fang X, Hu W, Chen J, et al. A retrospective analysis of kidney function and risk factors by chronic kidney disease epidemiology collaboration (CKD-EPI) equation in elderly Chinese patients. Ren Fail. 2015 37(8):1323-8.

45. Keller CR, Odden MC, Fried LF, Newman AB, Angleman S, Green CA, et al. Kidney function and markers of inflammation in elderly persons without chronic kidney disease: the health, aging, and body composition study. Kidney Int. 2007;71(3):239-44.

\section{Ready to submit your research? Choose BMC and benefit from:}

- fast, convenient online submission

- thorough peer review by experienced researchers in your field

- rapid publication on acceptance

- support for research data, including large and complex data types

- gold Open Access which fosters wider collaboration and increased citations

- maximum visibility for your research: over $100 \mathrm{M}$ website views per year

At BMC, research is always in progress.

Learn more biomedcentral.com/submissions 